\title{
Effect of Iron Content on Hot Tearing of High-Strength Al-Mg-Si Alloy
}

\author{
Hiromi Nagaumi ${ }^{1}$, Satoru Suzuki ${ }^{1}$, Toshimitsu Okane ${ }^{2}$ and Takateru Umeda ${ }^{3, *}$ \\ ${ }^{1}$ Nikkei Research \& Development Center (NRDC), Nippon Light Metal Company Ltd., Shizuoka 421-3291, Japan \\ ${ }^{2}$ Digital Manufacturing Research Center, National Institute of Advanced Industrial Science and Technology (AIST), \\ Tsukuba 305-8564, Japan \\ ${ }^{3}$ Department of Metallurgical Engineering, Faculty of Engineering, Chulalongkorn University, Bangkok, Thailand
}

\begin{abstract}
The effect of iron content on hot tearing of the high-strength Al-Mg-Si alloy was systematically investigated. The alloy with higher content of iron resulted in the severe occurrence of hot tearing during direct chill (DC) casting. Mechanical properties of this alloy in which iron content was changed were investigated during solidification using an electromagnetic induction heating tensile machine. Tensile strength and elongation were discussed in relation with solidification progress of which sequence of crystallization, crystallization temperature of formed phases and their crystallized amount were calculated by a thermodynamic calculation software Thermo-Calc. In order to confirm the calculation results of solidification path, a quenching test also was carried out. Furthermore, by comparing the fracture surfaces of the tensile testing sample and DC billet, the temperature range of crack initiation of the alloy was examined. Comparing the temperature range of crack initiation with the crystallization phase and its crystallization order, iron content influenced hot tearing significantly owing to the crystallization behavior of $\alpha(\mathrm{AlFeMn})$ in high-strength Al-Mg-Si alloy. [doi:10.2320/matertrans.47.2821]
\end{abstract}

(Received July 3, 2006; Accepted September 11, 2006; Published November 15, 2006)

Keywords: hot tearing, tensile strength, crack susceptibility, iron content, intermetallic compound, solidification path

\section{Introduction}

A major problem among aluminum alloy processing is hot tearing during casting because the crack is a serious factor which inhibits the productivity. Investigations on hot tearing have been reported in many previous studies ${ }^{1-12)}$ and it is clear that the hot tearing is generated when stress prevents the contraction of the alloy at the temperature near the solidus. When the alloy has a wide solidification temperature range and a small amount of liquid, the hot tearing is easy to occur. Alloy composition is also important to the crack susceptibility. For example, Spittle and Cushway ${ }^{13)}$ measured the hot tearing susceptibilities of $\mathrm{Al}-\mathrm{Cu}$ alloys $(0-15 \% \mathrm{Cu})$, and found that the hot tearing susceptibility decreased with increasing copper content, because at higher copper composition, a high volume fraction of eutectic liquid existed and resulted in ensuring interdendritic feeding and healing of tears. Oya et al. ${ }^{14)}$ investigated hot tearing tendency of Al-(0$33 \%) \mathrm{Cu}$ and $\mathrm{Al}-(0-13 \%) \mathrm{Si}$ alloys, and they also found the hot tearing tendency was decreased as the $\mathrm{Cu}$ and $\mathrm{Si}$ content increased. Oya's group ${ }^{15)}$ also investigated the effect of third element addition on hot tearing of binary $\mathrm{Al}-4.5 \% \mathrm{Cu}$ alloy, and they found that $\mathrm{Ti}, \mathrm{Mg}$ and $\mathrm{Si}$ improved the resistance to hot tearing, but $\mathrm{Sn}, \mathrm{Zn}, \mathrm{Fe}$, and Ni had poor resistance. These studies mentioned above were, however, based on binary alloys, and very few studies based on commercial aluminum alloys were reported.

In this study, the effect of iron content on hot tearing of the newly commercially developed high-strength Al-Mg-Si alloy was systematically investigated. Higher iron content caused hot tearing easily. In order to understand the hot tearing of this alloy, mechanical properties during solidification, the solidification behavior and their relationship were investigated. The intermetallic compound including iron, $\alpha(\mathrm{AlFeMn})$ compound, was found to play a vitally important role to hot tearing.

*Professor Emeritus, The University of Tokyo
Table 1 Chemical composition of high-strength Al-Mg-Si alloys.

\begin{tabular}{cccccccc}
\hline Alloy & $\mathrm{Si}$ & $\mathrm{Fe}$ & $\mathrm{Cu}$ & $\mathrm{Mg}$ & $\mathrm{Mn}$ & $\mathrm{Cr}$ & $\mathrm{Ti}$ \\
\hline $\mathrm{A}$ & 1.0 & 0.25 & 0.40 & 0.83 & 0.37 & 0.27 & 0.02 \\
$\mathrm{~B}$ & 1.0 & 0.18 & 0.40 & 0.83 & 0.37 & 0.27 & 0.02 \\
$\mathrm{C}$ & 1.0 & 0.15 & 0.40 & 0.83 & 0.37 & 0.27 & 0.02 \\
\hline
\end{tabular}

\section{Experimental Methods}

\subsection{Casting experiment}

The material used for this study was a high strength Al$\mathrm{Mg}-\mathrm{Si}$ alloy (called as HS65) which contained different content of iron. Billets of the high strength Al-Mg-Si alloys with the diameter of $325 \mathrm{~mm}$ were cast by the typical DC caster under following conditions: Casting temperature; $993 \mathrm{~K}$, Casting speed; $55 \mathrm{~mm} / \mathrm{min}$, Metal level; $15 \mathrm{~mm}$ and Water supply; $150 \mathrm{l} / \mathrm{min}$. Chemical compositions of cast billet are given in Table 1. In comparison with previously reported alloy (HS60), ${ }^{11,16)}$ Magnesium, silicon and copper contents in this alloy were decreased from 1.12 to 0.83 mass $\%$, from 1.23 to 1.0 mass $\%$ and from 0.79 to 0.40 mass $\%$, respectively, to reduce the hot tearing. The samples for microstructure observation were taken from the billet after casting and the crystallized phases were investigated by $\mathrm{X}$-ray diffraction method (XRD) and electron probe micro analysis (EPMA).

\subsection{Thermodynamic calculation}

Diffusion in solid for DC casting was so slow, in general, that the Gulliver-Scheil model which neglects diffusion in solid could be used for calculating solidification path, because the error was regarded as being little in a range of cooling rate of usual casting. ${ }^{17)}$ In this study, the commercial database software Thermo-Calc was used to calculate the solidification path under the non-equilibrium condition which was, however, supposed to be a local equilibrium at 


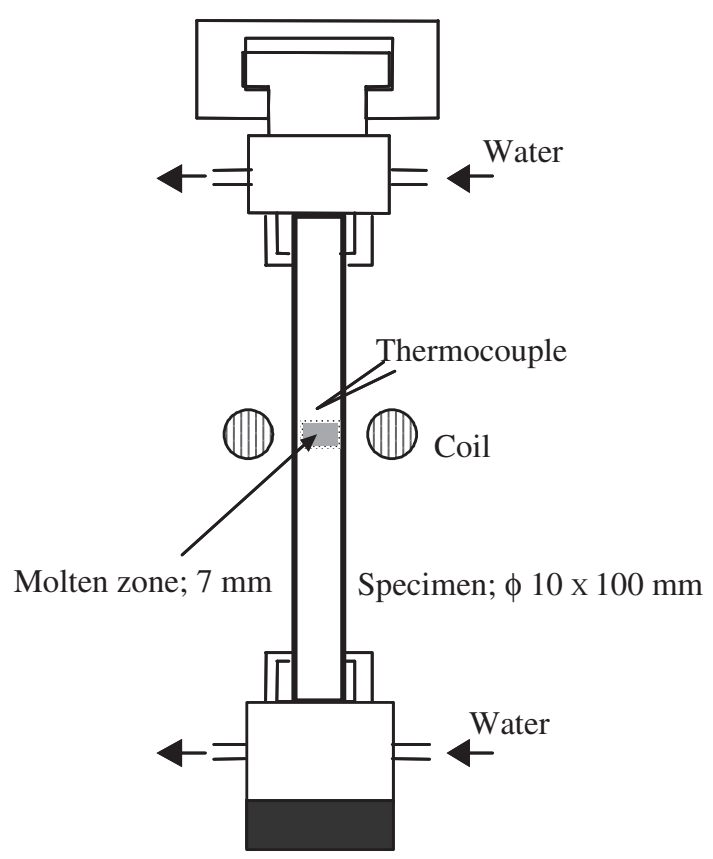

High resolution type of load cell; $5 \mathrm{kN}$

Fig. 1 Schematic diagram of high temperature tensile testing machine.

solid/liquid interface. The change of solidification path was simulated using the Gulliver-Scheil model owing to iron content from 0.1 to $0.3 \%$ (in mass $\%$ ) based on the reference of B alloy as shown in Table 1.

\subsection{Interrupted solidification}

In order to confirm the calculation results of solidification path, an interrupted solidification technique was applied. Several temperatures in the alloy freezing range were selected to establish the phase formation of which phase was determined by EPMA and XRD. A sample with $7 \mathrm{~mm}$ in diameter and $5 \mathrm{~mm}$ in length was set up in furnace and then first heated up to $973 \mathrm{~K}$ and then kept for $10 \mathrm{~min}$. Next, it was cooled at a rate of $1 \mathrm{~K} / \mathrm{s}$ to the test temperature before quenching. When temperature was reached to the prescribed one, the sample was kept for $30 \mathrm{~s}$ and then dropped into the water bath for quenching. The temperature control was carried out by the thermocouple installed at the molten zone of the sample and the cooling rate was over $150 \mathrm{~K} / \mathrm{s}$ during quenching. Quenched samples were mechanically polished, etched for microstructure observation and then supplied to EPMA analysis.

\subsection{Semi-solid tensile test}

A remelting type of high temperature tensile test during solidification was carried out by using the high temperature tensile test equipment with induction heating. Schematic diagram of high temperature tensile testing machine is shown in Fig. 1. At first, the specimen was heated up to temperature above its liquidus temperature and then kept for a certain period of time. Next, it was cooled down to the test temperature at cooling rate $1 \mathrm{~K} / \mathrm{s}$. By this means, a solidification structure was obtained. Finally, tensile load was applied at strain rate $10^{-2} \mathrm{~s}^{-1}$ and the load-displacement relation was recorded. Test sample had diameter of $10 \mathrm{~mm}$
Table 2 Casting results.

\begin{tabular}{cccc}
\hline Casting speed $(\mathrm{mm} / \mathrm{min})$ & A & B & C \\
\hline 70 & crack & crack & crack \\
60 & crack & crack & no crack \\
50 & crack & no crack & no crack \\
45 & crack & no crack & no crack \\
\hline
\end{tabular}

and length of $100 \mathrm{~mm}$. All the experiments were done under an argon atmosphere in the pressure of $0.1 \mathrm{MPa}$. Another experimental procedure, temperature measurement and its accuracy, evaluation of mechanical properties and etc. were found in previous papers. ${ }^{11,12,18,19)}$

The fracture surfaces after tensile testing and the broken billets were observed by the secondary electron microscope (SEM).

\section{Experimental Results}

According to the casting results as shown in Table 2 the billet was found to be prone to crack in the descending order of composition $\mathrm{A}$, composition $\mathrm{B}$, and composition $\mathrm{C}$. The composition A alloy showed the highest crack susceptibility because the crack was still generated even if the casting speed had changed to slower.

Figure 2 shows the relationship of tensile strength, elongation and temperature which was obtained by high temperature tensile test for A, B and C alloys. Zero Strength Temperature (ZST) is a minimum temperature above which shows no strength. ZST is 904,898 and $896 \mathrm{~K}$ for A, B and C Alloys, respectively. Tensile strength of each alloy increases gradually from ZST with decreasing of temperature. Tensile strength, then, increases steeply from around $858 \mathrm{~K}$ for $\mathrm{A}$ alloy, $813 \mathrm{~K}$ for $\mathrm{B}$ alloy and $834 \mathrm{~K}$ for $\mathrm{C}$ alloy. The gradual increase rate of tensile strength with temperature from ZST to the temperature of steep increase is indeed small for each alloy, however, its value changes in proportion to iron content; A is highest, B medium and C lowest.

Zero Ductility Temperature (ZDT) is a minimum temperature above which shows no elongation. ZDT is 890,886 and $891 \mathrm{~K}$ for A, B and C Alloys, respectively. As for the elongation each alloy shows a very small ductility from ZDT to $783 \mathrm{~K}$ so as the elongation is less $2 \%$. Just lower than ZDT, at first, each alloy shows its small peak and then decreases with decreasing of temperature from its peak temperature and then increases sharply from about $783 \mathrm{~K}$. The sharp increase temperature of elongation is lower than that of tensile strength.

ZST of each alloy is different from ZDT. They are 904 and $890 \mathrm{~K}$ for A alloy, 898 and $886 \mathrm{~K}$ for B alloy, 896 and $891 \mathrm{~K}$ for $\mathrm{C}$ alloy, respectively. Temperature difference between ZST and ZDT is 14,12 and $5 \mathrm{~K}$ for $\mathrm{A}, \mathrm{B}$, and $\mathrm{C}$ alloys, respectively and alloy $\mathrm{A}$ is widest among the three alloys. Comparing with Table 2 it can be said that the crack susceptibility of this alloy corresponds to higher ZST, higher increase rate of tensile strength from ZST and wider temperature range between ZST and ZDT. The relation between mechanical properties and solidification progress will be discussed later. 

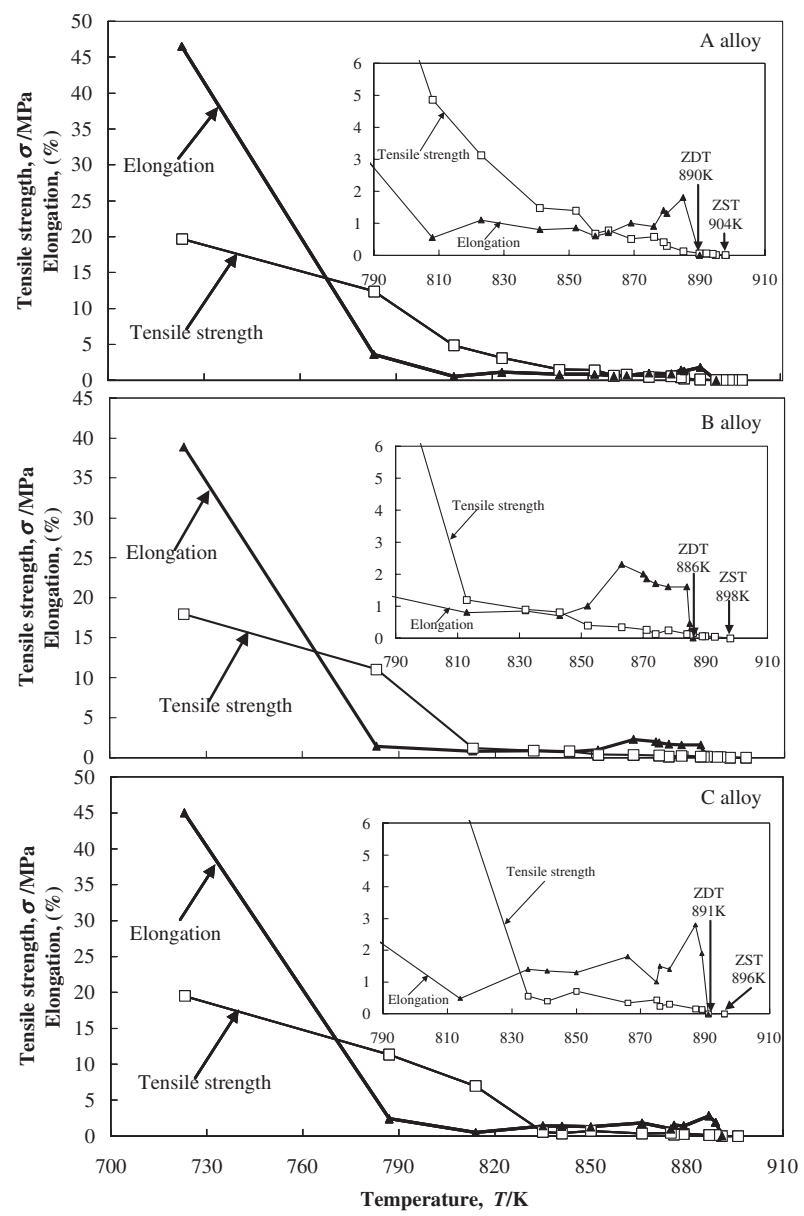

Fig. 2 Relation of tensile strength, elongation and temperature of A, B, C alloys.

Figure 3 shows comparison of fracture surfaces between the broken billet and the tensile test at different temperatures of composition B alloy. The fracture surface of the broken billet as shown in a) has a rupture structure where intergranular fracture with remaining liquid around interden- dritic regions was observed, namely the crack of this alloy occurs in the solid/liquid coexisting (mushy) state. The fracture surfaces of tensile testing at different temperature as shown in (b)-(f) show intergranular fracture with remaining liquid around interdendritic regions and there are many intermetallic compounds crystallized which are observed except the temperature of $885 \mathrm{~K}$. As temperature decreases the fracture surface tends to flatten, the amount of intermetallic compounds around grains increases. Comparing to the high temperature tensile test, the fracture surface of broken billet is well resembled with one after tensile test at temperature $868 \mathrm{~K}$ (see (c)) in Fig. 3, so it is considered that the crack of DC billet is generated around the temperature $868 \mathrm{~K}$. The crack is easy to be generated around the temperature $868 \mathrm{~K}$, because tensile strength and elongation of the alloy are very small around the temperature $868 \mathrm{~K}$ as show in Fig. 2.

SEM micrograph is shown in Fig. 4. The following intermetallic constitutes are observed: $\alpha(\mathrm{AlFeMn}), \beta(\mathrm{AlFe}-$ $\mathrm{Si}), \mathrm{Mg}_{2} \mathrm{Si}, \mathrm{Si}, \mathrm{Al}_{5} \mathrm{Cu}_{2} \mathrm{Mg}_{8} \mathrm{Si}_{6}$ and $\mathrm{Al}_{2} \mathrm{Cu}$. $\alpha$ (AlFeMn) compound shows a needle shape morphology and $\beta(\mathrm{AlFeSi})$ compound shows a needle and also Chinese script shapes.

Figure 5 shows the calculated crystallization temperature of phases of B alloy by the Gulliver-Scheil model. Nonequilibrium solidification completion temperature and liquidus temperature are 783 and $923 \mathrm{~K}$, respectively. As shown in Fig. 5, the phase formation sequence during solidification is $\mathrm{L} \rightarrow \mathrm{L}+(\mathrm{Al}) \rightarrow \mathrm{L}+(\mathrm{Al})+\alpha(\mathrm{AlFeMn}) \rightarrow \mathrm{L}+(\mathrm{Al})+$ $\alpha(\mathrm{AlFeMn})+\beta(\mathrm{AlFeSi}) \rightarrow \mathrm{L}+(\mathrm{Al})+\alpha(\mathrm{AlFeMn})+$ $\beta(\mathrm{AlFeSi})+\mathrm{Mg}_{2} \mathrm{Si} \rightarrow \mathrm{L}+(\mathrm{Al})+\alpha(\mathrm{AlFeMn})+\beta(\mathrm{AlFeSi})$ $+\mathrm{Mg}_{2} \mathrm{Si}+\mathrm{Al}_{8} \mathrm{FeMg}_{3} \mathrm{Si}_{6} \rightarrow \mathrm{L}+(\mathrm{Al})+\alpha(\mathrm{AlFeMn})+$ $\beta(\mathrm{AlFeSi})+\mathrm{Mg}_{2} \mathrm{Si}+\mathrm{Al}_{8} \mathrm{FeMg}_{3} \mathrm{Si}_{6}+\mathrm{Si} \rightarrow \mathrm{L}+(\mathrm{Al})+$ $\alpha(\mathrm{AlFeMn})+\beta(\mathrm{AlFeSi})+\mathrm{Mg}_{2} \mathrm{Si}+\mathrm{Al}_{8} \mathrm{FeMg}_{3} \mathrm{Si}_{6}+\mathrm{Si}+$ $\mathrm{Al}_{5} \mathrm{Cu}_{2} \mathrm{Mg}_{8} \mathrm{Si}_{6} \rightarrow \mathrm{L}+(\mathrm{Al})+\alpha(\mathrm{AlFeMn})+\beta(\mathrm{AlFeSi})+$ $\mathrm{Mg}_{2} \mathrm{Si}+\mathrm{Al}_{8} \mathrm{FeMg}_{3} \mathrm{Si}_{6}+\mathrm{Si}+\mathrm{Al}_{5} \mathrm{Cu}_{2} \mathrm{Mg}_{8} \mathrm{Si}_{6}+\mathrm{Al}_{2} \mathrm{Cu}$. Table 3 shows the crystallization temperature of phase formed and its amount. The finally formed phase of $\mathrm{Al}_{2} \mathrm{Cu}$ starts to crystallize at about $788 \mathrm{~K}$ and then the solidification finishes at $783 \mathrm{~K}$. (See also $\mathrm{Al}_{2} \mathrm{Cu}$ in Figs. 5 and 6.) By

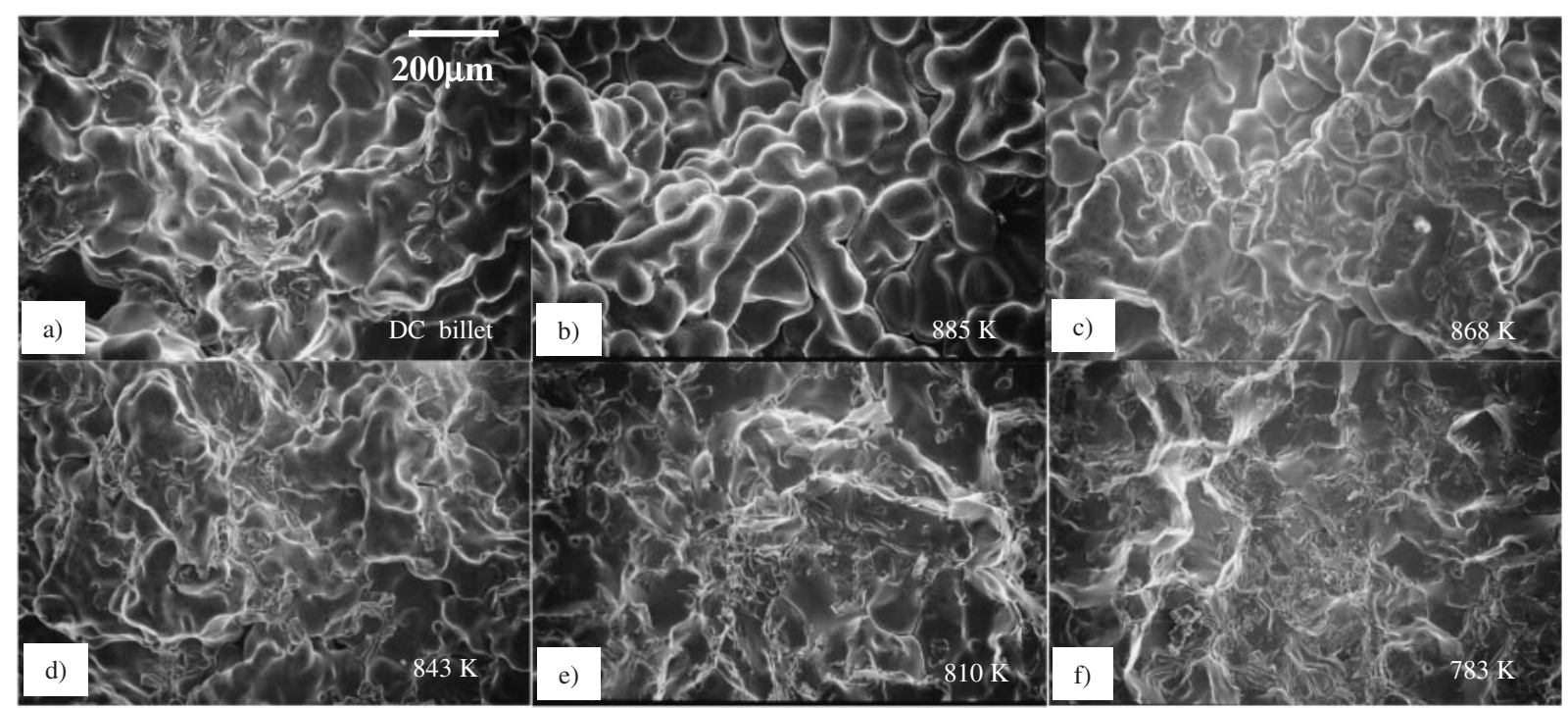

Fig. 3 Fracture surfaces of broken billet, (a), and tensile test specimens, (b)-(f), of B alloy. (a) broken billet, (b) tensile test at $885 \mathrm{~K}$, (c) tensile test at $868 \mathrm{~K}$, (d) tensile test at $843 \mathrm{~K}$, (e) tensile test at $810 \mathrm{~K}$, (f) tensile test at $783 \mathrm{~K}$. 

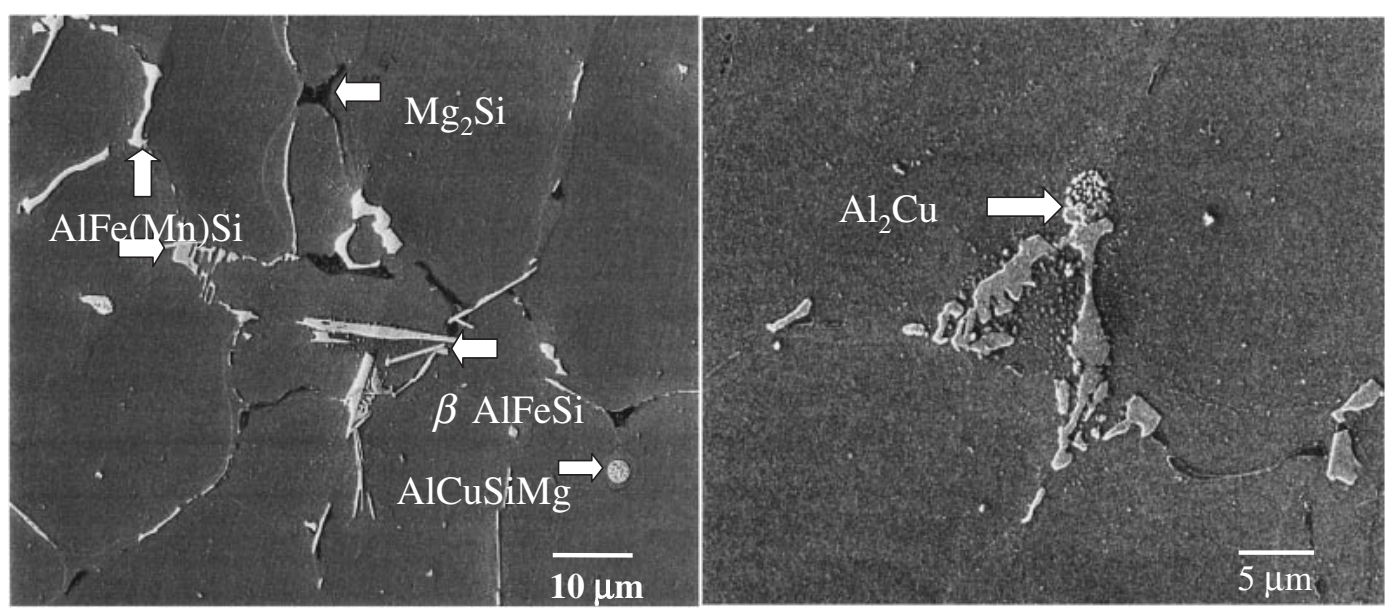

Fig. 4 Electron micrograph of B alloy.

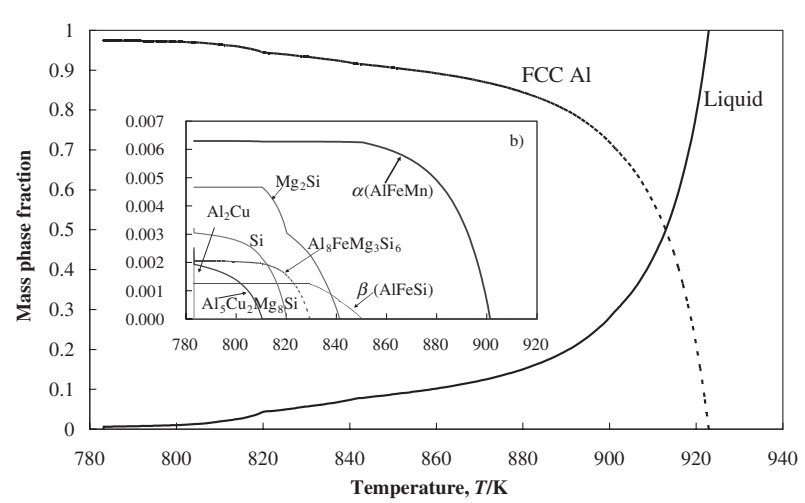

Fig. 5 Phase fraction of the B alloy as a function of temperature under the Gulliver-Scheil's condition; the insert shows an enlarged view for the temperature interval from 783 to $900 \mathrm{~K}$.

Table 3 Solidification sequence of B alloy and mass percentage of each phase at complete solidification temperature.

\begin{tabular}{lccc}
\hline \multirow{2}{*}{ Phase } & \multicolumn{2}{c}{ Calculated } & \\
\cline { 2 - 3 } & $\begin{array}{c}\text { Crystallization } \\
\text { temperature }(\mathrm{K})\end{array}$ & $\begin{array}{c}\text { Amount } \\
\text { (mass\%) }\end{array}$ & Confirmed \\
\hline FCC Aluminum & 923 & 97.8 & $\mathrm{Y}$ \\
$\alpha(\mathrm{AlFeMn})$ & 901 & 0.61 & $\mathrm{Y}$ \\
$\beta(\mathrm{AlFeSi})$ & 850 & 0.124 & $\mathrm{Y}$ \\
$\mathrm{Mg}_{2} \mathrm{Si}$ & 841 & 0.466 & $\mathrm{Y}$ \\
$\mathrm{Al}_{8} \mathrm{FeMg} \mathrm{Si}_{6}$ & 829 & 0.206 & $\mathrm{~N}$ \\
$\mathrm{Si}_{\mathrm{Al}} \mathrm{Cu}_{2} \mathrm{Mg}_{8} \mathrm{Si}_{6}$ & 820 & 0.304 & $\mathrm{Y}$ \\
\hline $\mathrm{Y}: \mathrm{Confrm}$ & 810 & 0.193 & $\mathrm{Y}$ \\
\hline
\end{tabular}

Y: Confirmed by EPMA and EDX.

$\mathrm{N}$ : Not observed in solidification microstructure.

comparing the solidification sequence between HS65 (present study) and HS60 (previous study), a small reduction of the content of magnesium, silicon and copper, resulted in the crystallization of $\beta\left(\mathrm{AlFeSi}\right.$ ) prior to $\mathrm{Mg}_{2} \mathrm{Si}^{16}$ )

In order to confirm the calculated results, several temperatures were selected for the quenching test (quenched temperatures as indicated in Fig. 6) and the quenched samples were analyzed by XRD and EPMA. Microstructures obtained and the results of phase identification are shown in

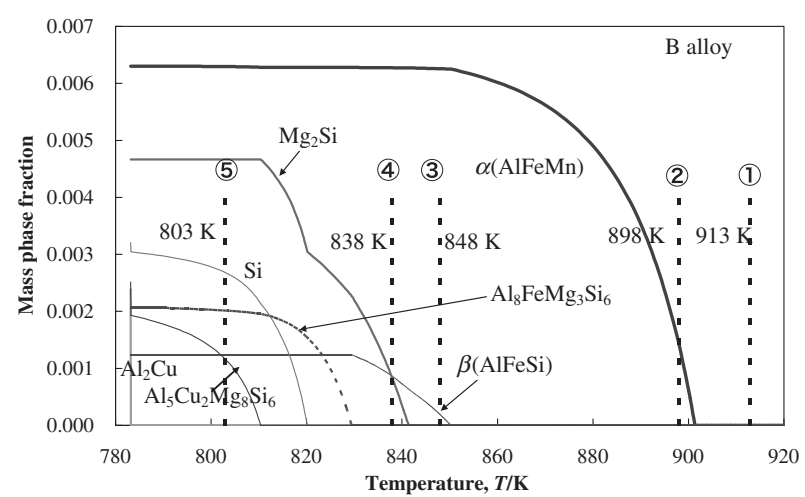

Fig. 6 Interrupted solidification temperatures shown on the graph of relation between phase fraction and temperature.

Fig. 7. At temperature of $913 \mathrm{~K}$ (solid fraction 0.50), the liquid remains in a large area and no any phase appeared except the primary FCC solid-solution aluminum phase (FCC $\mathrm{Al})$ is observed. When the temperature decreases to $898 \mathrm{~K}$ (solid fraction 0.74 ), only the phase $\alpha(\mathrm{AlFeMn})$ other than FCC $\mathrm{Al}$ is observed. Furthermore, when the temperature is down to $848 \mathrm{~K}$ (solid fraction 0.91 ), $\beta$ (AlFeSi) phase (usually called as Chinese-script) is observed. When the temperature is down to $838 \mathrm{~K}, \beta(\mathrm{AlFeSi})$ and $\mathrm{Mg}_{2} \mathrm{Si}$ phases are observed. When the temperature decreases to $803 \mathrm{~K}$ (solid fraction 0.99), all phases are observed except $\mathrm{Al}_{2} \mathrm{Cu}$ phase which is formed in the final solidification stage as shown in Fig. 4(b). In comparison with above quenching experimental observation results, with together Fig. 4(b), and calculated results by the Thermo-Calc, it can be said that the results of this calculation using the Gulliver-Scheil model are appropriate, because the experimental results (Fig. 7) are good well with the calculation results (Fig. 5.)

\section{Discussion}

\subsection{Relation between mechanical properties and solid fraction}

The relation between solid fraction and temperature of the three alloys was calculated for understanding and comparing the solidification progress of each alloy and is shown in 


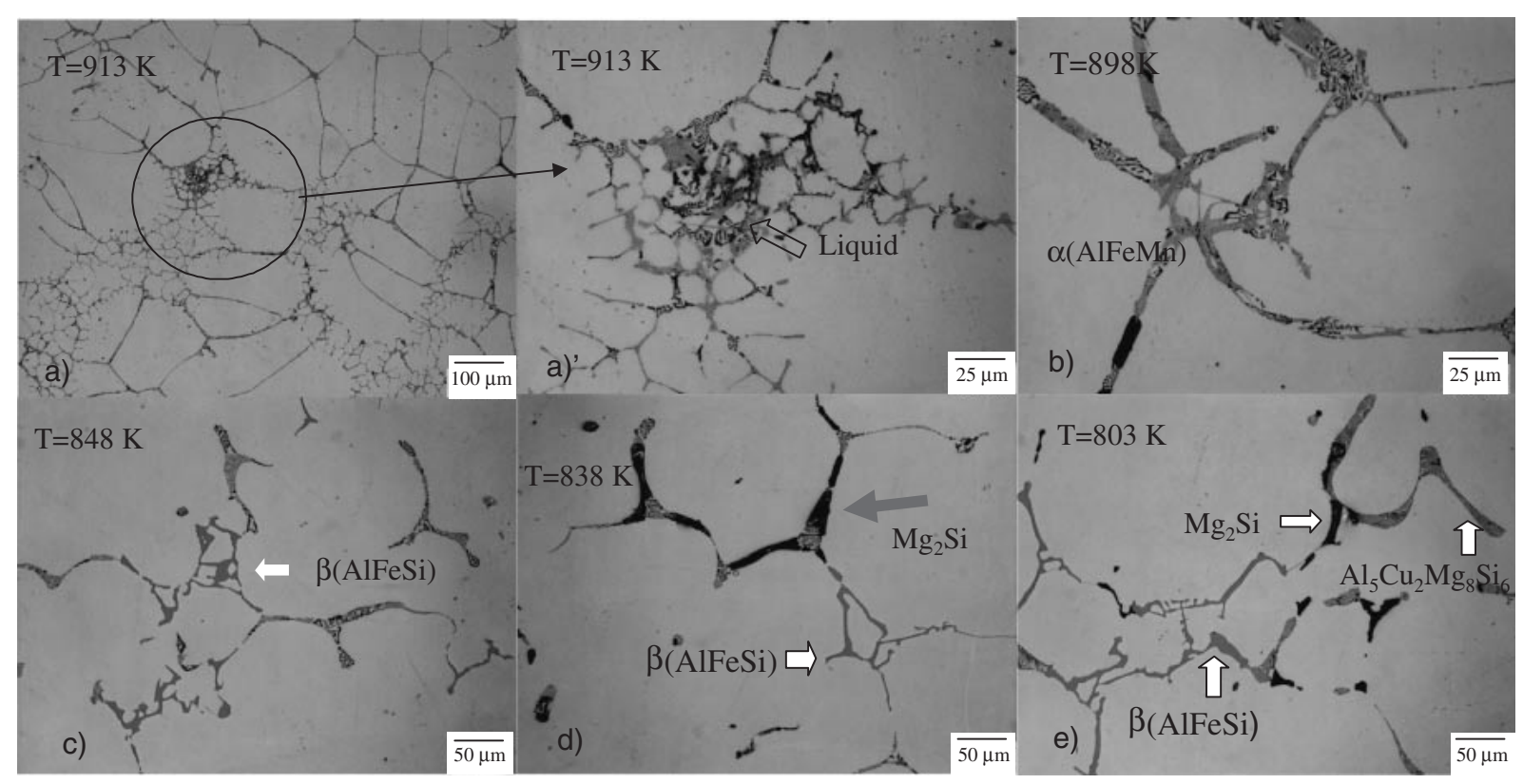

Fig. 7 Micrographs quenched from interrupted solidification temperatures of B alloy; quenched from (a) $913 \mathrm{~K}$ (solid fraction, $f_{\mathrm{s}}$, 0.50), (a) $)^{\prime}$ magnified the circle part in (a), (b) $898 \mathrm{~K}\left(f_{\mathrm{s}}, 0.74\right)$, (c) $848 \mathrm{~K}\left(f_{\mathrm{s}}, 0.91\right)$, (d) $838 \mathrm{~K}\left(f_{\mathrm{s}}, 0.93\right),(\mathrm{e}) 803 \mathrm{~K},\left(f_{\mathrm{s}}, 0.99\right)$.

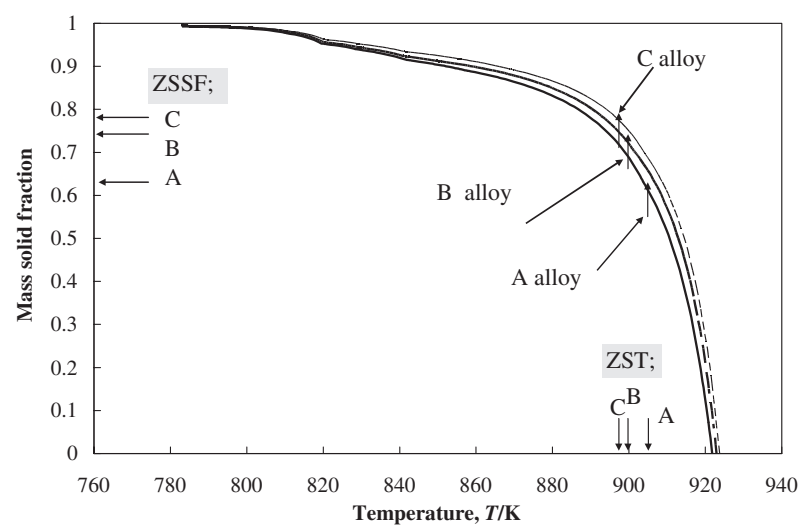

Fig. 8 Relation between mass solid fraction and temperature.

Fig. 8. As the iron content increases, the liquids temperature decreases a little, around $20 \mathrm{~K}$ decrease per 1 mass $\%$ iron in this composition range, but the non-solidification completion temperature is same for the three alloys, that is, $783 \mathrm{~K}$ for eutectic crystallization completion of $\mathrm{Al}_{2} \mathrm{Cu}$. ZST of $\mathrm{A}, \mathrm{B}$ and $\mathrm{C}$ alloys, as previous mentioned, was 904, 898 and $896 \mathrm{~K}$, respectively and the corresponding mass solid fraction is found to be $0.63,0.74$ and 0.79 , respectively. The Zero Strength Solid Fraction (ZSSF) above which shows no strength is a clear parameter of the crack susceptibility of this alloy, which is same the order of ZSSF (See Table 2); an alloy with smaller solid fraction corresponding to ZST becomes sensible to hot tearing. Note that ZSSF of each alloy was considerably different though the iron content was not so different. By changing iron content from 0.25 only to 0.18 or 0.15 mass $\%$, ZSSF changed from 0.63 to 0.74 or 0.79 , respectively and seemed to change much; especially the big difference more than 0.1 of solid fraction happened between A and B alloys. Therefore it can be said the crack susceptibility is easily understood by comparing the ZSSF of each

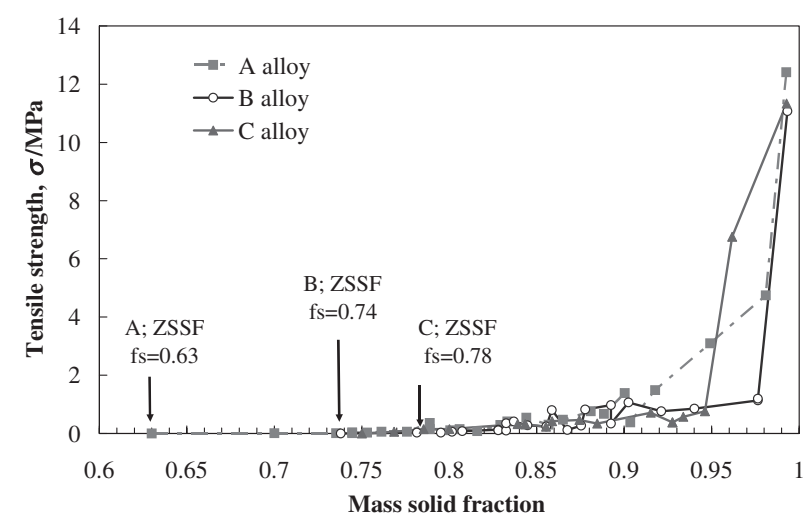

Fig. 9 Tensile strength as a function of fraction solid of each alloy.

alloy. In our previous study, ${ }^{12)}$ we found that the crack susceptibility among 6063, 6061, HS60, 7025 and 7075 became higher as the ZSSF of each alloy was lower.

Figure 9 shows the relation between tensile strength and solid fraction of each alloy in which tensile strength is very small when the solid fraction is below around 0.9. It can be seen that the tensile strength of each alloy increases with the solid fraction increase and the tensile strength steeply increases when the solid fraction is over $0.90-0.95 ; 0.89$ $(858 \mathrm{~K})$ for A, $0.97(813 \mathrm{~K})$ for B and $0.95(834 \mathrm{~K})$ for C. This solid fraction of steep increase in strength seemed to be scattered, however, $0.90-0.95$ if excluded with 0.97 for B alloy. This solid fraction seemed to correspond to the "coalesce" solid fraction at which solid bridging started to form extensively between neighboring dendrites. ${ }^{20)}$

The corresponding solid fraction of ZDT, that is, ZDSF (Zero Ductility Solid Fraction), was evaluated as 0.78, 0.82 and 0.82 in accordance with 890,886 and $891 \mathrm{~K}$ for A, B and $\mathrm{C}$ alloys, respectively. Solid fraction of steep increase in elongation $(783 \mathrm{~K})$ was unity for all experimental alloys. 


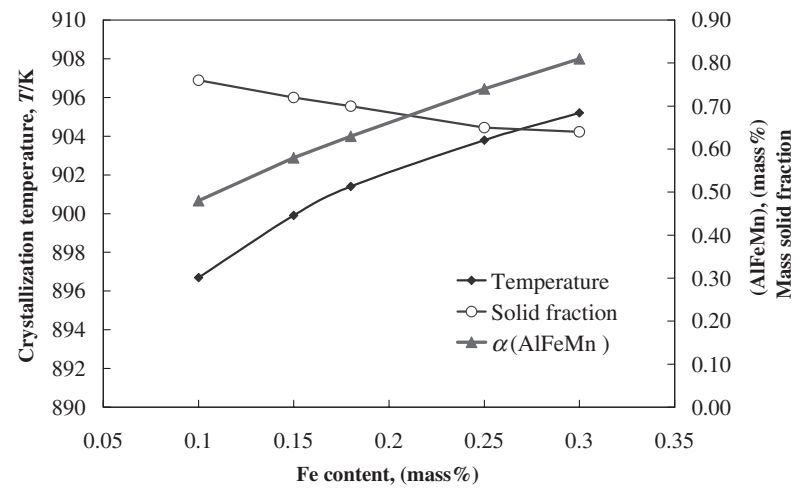

Fig. 10 Change of crystallization temperature of $\alpha(\mathrm{AlFeMn})$, its crystallized mass percentage and fraction solid of its starting crystallization as a function of iron content.

ZDSF of this alloy was smaller than that of carbon steels, which was almost unity ${ }^{18)}$ and corresponded with the solid fraction of steep increase in elongation of this aluminum alloy.

Temperature range or solid fraction range between ZST and ZDT was an important factor for hot tearing because the alloy showed strength but no ductility. Solid fraction range between ZSSF and ZDSF was $0.15,0.08$ and 0.03 for A, B and $\mathrm{C}$ alloys, respectively. The $\mathrm{A}$ alloy with highest crack susceptibility had a wider solid fraction range between ZSSF and ZDSF. Crack susceptibility was in proportion to the solid fraction range. On the other hand, from the comparison of the observation result of fracture surfaces, the temperature at which crack initiation in DC billet, it was fairly qualitative, was around $868 \mathrm{~K}$, and the corresponding solid fraction calculated by Thermo-Calc. was 0.85 for the B alloy. Solidification progress from ZSSF or ZST to solid fraction or temperature of sharp increase in elongation was another measure, at least quantitatively, for hot tearing instead of the difference of solid fraction between ZSSF and ZDSF or the temperature difference between ZST and ZDT.

\section{2 $\alpha($ AlFeMn) crystallization and crack susceptibility of Al-Mg-Si alloy}

In order to investigate the effect of iron content on the crack susceptibility of the alloy, the change of crystallization temperature or solid fraction and crystallized amount of $\alpha(\mathrm{AlFeMn})$ was calculated with the different content of iron. Fig. 10 shows the effect of iron content on crystallization of $\alpha(\mathrm{AlFeMn})$; temperature or solid fraction of crystallization start and its amount. The crystallization temperature of $\alpha(\mathrm{AlFeMn})$ increases with increasing iron content, but its corresponding solid fraction decreases. As for crystallized amount of $\alpha(\mathrm{AlFeMn})$, it increases with increasing iron content. It is interesting to note that ZST or ZSSF is determined just or a little after $\alpha(\mathrm{AlFeMn})$ crystallized, by comparing Fig. 10 with Fig. 9.

$\alpha(\mathrm{AlFeMn})$ intermetallic compound, mainly due to the needle shape, could bridge a gap between primarily solidified dendrites, in particular, where the dendrite network for higher iron content alloy was not perfectly formed since the solid fraction was still low (around 0.63) when iron content increased over $0.25 \%$. It resulted in higher ZST with a higher iron content alloy since $\alpha(\mathrm{AlFeMn})$ crystallized with higher temperature in a higher iron alloy. That is, it was regarded that the grain boundary became fragile when the intermetallic compound of $\alpha(\mathrm{AlFeMn})$ was crystallized in needle shape into grain boundary and the crack was easily generated in the casting. The details, especially on the bridging between dendrites through $\alpha(\mathrm{AlFeMn})$ compound and its relation to mechanical properties will be discussed in the next paper.

\section{Conclusions}

To investigate hot tearing during DC billet, a tensile test in the mushy zone of the high strength Al-Mg-Si alloy was carried out. Solidification path was also calculated to relate between solidification sequence and mechanical properties in the mushy zone by using a thermodynamic calculation software Thermo-Calc. By comparing with temperature range of crack initiation, crystallization phase and crystallization order, the effect of the iron content on the crack susceptibility of the high strength Al-Mg-Si alloy was clarified. The main results obtained are shown below.

(1) Higher content of iron of high strength Al-Mg-Si alloy occurred hot tearing during casting. Crack susceptibility of DC billet was in proportion to iron content.

(2) Zero strength temperature (ZST) of A, B and C alloys was 904, 898 and $896 \mathrm{~K}$, respectively. Zero ductility temperature (ZDT) of A, B and C alloys was 890,886 and $891 \mathrm{~K}$, respectively.

(3) Solid fraction of ZST of A, B and C alloys was 0.63 to 0.74 or 0.79 , respectively. Solid fraction of ZDT was $0.78,0.82$ and 0.82 , respectively.

(4) The temperature in which the crack initiated was around $868 \mathrm{~K}$, at which corresponding solid fraction was 0.85 for B alloy, and the alloy had very low strength and elongation around $868 \mathrm{~K}$.

(5) The crack susceptibility of this alloy corresponded to higher ZST, higher increase rate of tensile strength from ZST and wider temperature range between ZST and ZDT. The crack susceptibility was most sensibly expressed as the zero strength solid fraction (ZSSF) above which no strength appeared.

(6) The casting crack of the high-strength Al-Mg-Si alloy was strongly influenced by the crystallization of $\alpha(\mathrm{AlFeMn})$ phase, which crystallized at higher temperature with increase in the iron content. Needle shaped $\alpha(\mathrm{AlFeMn})$ could bridge a gap between primarily solidified dendrites. It resulted in higher ZST with a higher iron content alloy. That is, it was regarded that the grain boundary became fragile when the intermetallic compound of $\alpha(\mathrm{AlFeMn})$ was crystallized in needle shape into grain boundary and the crack was easy to be generated in the casting.

\section{REFERENCES}

1) S. A. Metz and M. C. Flemings: AFS Trans. 77 (1969) 329-334.

2) M. Kubota and S. Kitaoka: AFS Trans. 81 (1973) 424-429.

3) T. W. Clyne and G. J. Davies: Brit. Foundryman. 74 (1981) 65-73.

4) W. Schneider and E. K. Jensen: Light Metals 1990, ed. by C. M. Bickert, (TMS, Warrendale, 1990) pp. 931-936. 
5) J. Campbell and T. W. Clyne: Cast Metals. 3 (1991) 224-230.

6) S. Upadhya, S. Cheng and U. Chandra: Light Metals 1995, ed. by J. W. Evans, (TMS, Warrendale, 1995) pp. 961-967.

7) L. I. Novikov and O. E. Grushko: Mater. Sci. Techol. 11 (1995) 926932.

8) M. Rappaz, J. M. Drezet and M. Gremaud: Metall. Trans. A 30A (1999) 449-455.

9) H. Nagaumi, K. Aoki, K. Komatsu and N. Hagisawa: Mater. Sci. Forum 331-337 (2000) 173-177.

10) J.-M. Drezet and M. Rappaz: Light Metals 2001, ed. by J. Anjier, (TMS, Warrendale, 2001) pp. 887-893.

11) H. Nagaumi and T. Umeda: Journal of Light Metals 2 (2002) 161-167.

12) H. Nagaumi and T. Umeda: Mater. Sci. Forum 426-432 (2003) 65-70.

13) J. A. Spittle and A. A. Cushway: Metals Technology 10 (1983) 6-13.

14) S. Oya, T. Fujii, F. Kato and M. Ohtaki: J. Jpn. Inst. Light Met. 33 (1983) 705-711.
15) S. Oya, T. Fujii, M. Ohtaki and S. Baba: J. Jpn. Inst. Light Met. 34 (1983) 511-516.

16) H. Nagaumi, P. Suvanchai, T, Okane and T. Umeda; submitted to Mater. Trans.

17) For example, W. Kurz and D. J. Fisher: Fundamentals of Solidification, Fourth Revised Edition, (Trans Tech Publications Ltd, UetikonZuerich, Switzerland, 1998) pp. 122-130.

18) G. Shin, T. Kajitani, T. Suzuki and T. Umeda: Tetsu to Hagane 78 (1992) 587-593.

19) P. Suvanchai, T. Okane and T. Umeda: Proceedings of the 4th Decennial International Conference on Solidification Processing, Sheffield, July 1997, ed. by J. Beech and H. Jones, Department of Engineering Materials, University of Sheffield (1997) pp. 190-194.

20) M. Rappaz, A. Jacot and W. J. Boettinger: Metall. Mater. Trans. A 34A (2003) 67-79. 